Published in : Crustaceana (2010), Volume 83, Issue 1, pp 39-47.

Status : Postprint (Author's Version)

\title{
SAMPLING METHODS FOR AMPHIPODS OF POSIDONIA OCEANICA MEADOWS: A COMPARATIVE STUDY
}

\author{
Loïc MICHEL ${ }^{1,3}$, Gilles LEPOINT² ${ }^{2}$ Patrick DAUBY ${ }^{1} \&$ Nicolas STURARO ${ }^{2}$ \\ ${ }^{1}$ Laboratory of Systematics and Animal Diversity, MARE Centre, University of Liège, Allée du 6 Août 13, B-4000 Liège, Belgium \\ ${ }^{2}$ Laboratory of Oceanology, MARE Centre, University of Liège, Allée du 6 Août 13, B-4000 Liège, Belgium \\ ${ }^{3}$ Corresponding author; e-mail: Loic.Michel@ulg.ac.be
}

\begin{abstract}
Efficient sampling of amphipod crustaceans associated with Posidonia oceanica (L.) Delile meadows is difficult, due to their complex community structure and to the heterogeneity of the meadows. Here we compare three sampling techniques: the hand-towed net, the air-lift, and light traps.

Each of the methods shows specific advantages and disadvantages, hence the most important feature to consider in the choice of the method would be its adequacy with regard to the study purpose. Moreover, the most accurate way to sample amphipods from $P$. oceanica meadows could be to combine several methods, keeping in mind their respective strengths and weaknesses, and to adapt the sampling to the aims of the study at issue.
\end{abstract}

\section{RÉSUMÉ}

II est difficile d'échantillonner les crustacés amphipodes associés aux herbiers à Posidonia oceanica (L.) Delile de manière efficace, en raison de la structure complexe de leur communauté et l'hétérogénéité des herbiers. Dans le cadre de cet article, nous comparons trois méthodes de prélèvement : le filet fauchoir, la suceuse à air comprimé et les pièges à lumière.

Chaque méthode montre des avantages et des inconvénients spécifiques, ce qui implique que l'élément le plus important à prendre en compte dans le choix d'une méthode est l'adéquation avec le but de l'étude. De plus, la manière la plus précise d'échantillonner les amphipodes des herbiers à $P$. oceanica pourrait être de combiner plusieurs méthodes, en gardant à l'esprit leurs forces et leurs faiblesses respectives, et d'adapter l'échantillonnage aux buts de l'étude.

\section{INTRODUCTION}

Posidonia oceanica (L.) Delile meadows are important ecosystems of the Mediterranean coastal zones, notably regarding primary production. These meadows are associated with high biodiversity and biomass of vagile invertebrates, which are considered key-components of these ecosystems, in particular in transfers of organic matter from producers to higher level consumers. Among these invertebrates, amphipod crustaceans are one of the most abundant and diverse groups, and therefore play an important role in the functioning of the meadow ecosystem (Gambi et al., 1992; Jernakoff et al., 1996).

However, the structure of the amphipod community is complex (Scipione \& Fresi, 1984). Nocturnal rise of individuals from the lower layers of the meadow to the foliar stratum is a common phenomenon (Sánchez-Jerez et al., 1999b). Horizontal migrations from adjacent, unvegetated habitats also exist. Furthermore, seagrass meadows are spatially heterogeneous ecosystems, featuring complex successions of numerous microhabitats (Sánchez-Jerez et al., 1999a).

The study of these invertebrates thus requires adequate and reliable, i.e., tested sampling techniques. Most past work in this field tends to concentrate on the use of a single method, and to consider the sampling done as representative of the community (e.g., Russo et al., 1991). Here, we focus on the sampling of highly motile amphipod crustaceans by comparing three non-destructive techniques: the hand-towed net, the air-lift, and light traps. 


\section{MATERIAL AND METHODS}

\section{Site description}

The study site was located in front of the marine research station STARESO (University of Liège), in Revellata Bay, on the north-western side of Corsica (Gulf of Calvi, France) $\left(42^{\circ} 35^{\prime} \mathrm{N}\right.$, $8^{\circ} 45^{\prime} E$ ). Samples were collected by SCUBA diving in March 2007 in the $P$. oceanica meadow, at depths ranging from 10 to $12 \mathrm{~m}$. Weather conditions were homogeneous during the sampling period, and also normal for the location and season considered. The sampled meadow is characterized by a continuous extension, reaching a density of $302 \pm 199$ shoots $\mathrm{m}^{-2}$ at sampling depth (mean \pm standard deviation of 45 measurements).

\section{Sampling techniques}

Hand-towed net. - The technique used here was a slight modification of the one described by Russo et al. (1985). The net itself is shown in fig. 1. It can be held and operated by a single diver. Sampling consisted of a series of strokes, given in order to shake the $P$. oceanica leaves from the basis, with the net held to form an angle of ca. $45^{\circ}$ with the bottom. A fixed meadow surface of $9 \mathrm{~m}^{2}$ was covered for each sample. One sample was taken on 22.III.2007 during the day (at 2:30 P.M.), and another on 25.III.2007 during the night (at 9:00 P.M.).

Air-Lift. - The air-lift sampler used was originally described in Bussers et al. (1983), and is depicted in fig. 1. The sampling area of the meadow was previously delimited by a PVC cylinder (height: $48 \mathrm{~cm}$, diameter: $40 \mathrm{~cm}$ ). Three sampling areas, delimiting a total surface of $0.386 \mathrm{~cm}^{2}$, were sucked up by the air-lift under constant airflow and during 2 minutes. Particular attention was taken to avoid the accumulation of large amounts of sediment in the collecting bag. The operation required two divers: one for the manipulation of the air-lift, the other for the cylinder. The collecting bag attached to the air-lift was made of $500 \mu \mathrm{m}$ mesh plankton net and has a lateral pocket where sucked-up amphipods accumulate, outside the high turbulence caused by the air escaping from the collecting bag. The sample was collected on 30.III.2007 at 10:30 A.M.

Light traps. - The light traps were made of transparent 1.5 litre plastic bottles, placed in reverse position (cf. fig. 1). Each trap presented vertical rectangular slits $(1 \mathrm{~cm}$ wide $\times 15 \mathrm{~cm}$ long) in its upper part, and a diving emergency light stick was fixed in the bottleneck. These sticks emit light for $>12$ hours, and the vagile invertebrates, attracted by the light, enter the trap, gather in the bottleneck, and seem unable to exit from the trap. Eight traps were scattered over a $9 \mathrm{~m}^{2}$ surface. They were anchored to the bottom using a $2 \mathrm{~kg}$ lead weight, and a float attached to the top of the trap insured that it remained vertical in the meadow canopy (cf. fig. I). The traps were placed at twilight (6:30 P.M.) on 24.III.2007 and recovered the next morning at 8:00 A.M.

\section{Sample processing}

All samples were sieved on a $500 \mu \mathrm{m}$ mesh and bulk fixed for at least $24 \mathrm{~h}$ in a formaldehyde solution ( $4 \%$ in filtered seawater). Amphipods were then sorted and transferred to a stocking solution $(70 \%$ ethanol $+1 \%$ glycerine). Identification was performed to species level, using the keys and monographs of Bellan-Santini et al. (1982, 1989, 1993, 1998), Krapp-Schickel \& Sorbe (2006), and Myers et al. (2001). The fragile individuals of the genus Apherusa Walker, 1891, particularly abundant in our samples, constitute an exception. The largest part (more than $85 \%$ ) belonged to the species Apherusa chiereghinii Giordani-Soika, 1950. Some individuals were immature juveniles, and some others were damaged: in both these cases, the organisms could not be brought to species with sufficient accuracy, and were hence recorded as Apherusa sp.

\section{Data treatment}

To assess the key features of the community and to compare samples among each other, we used three univariate diversity indices: Margalef's specific richness index, Shannon-Wiener's diversity index, and Pielou's evenness index (Clarke \& Warwick, 2001). Diversity indices have been calculated using PRIMER 5.0 (PRIMER-E Ltd., Plymouth). 

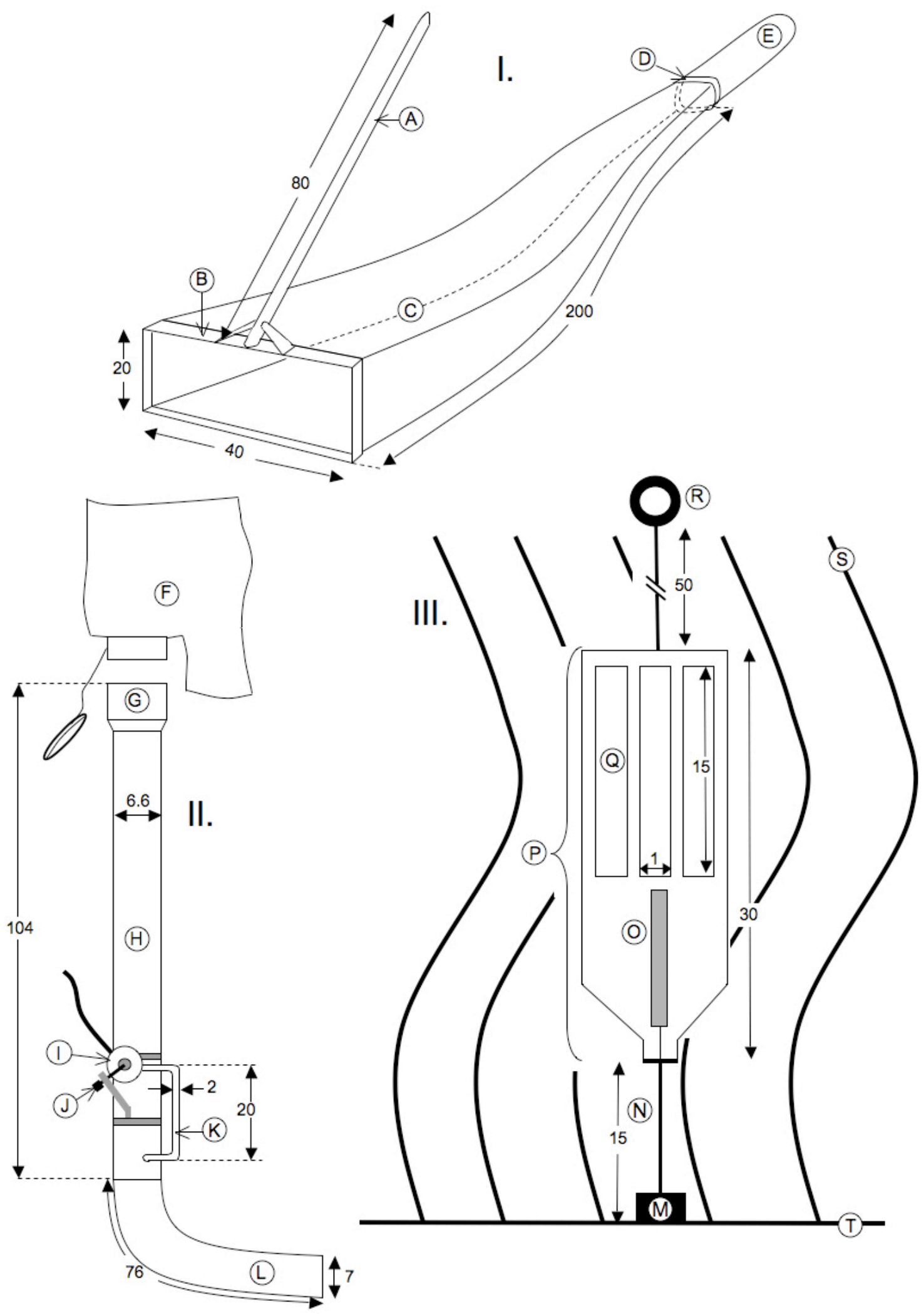

Fig. 1. Schematic representation of the sampling devices used in this study. I, hand-towed net; II, airlift; III, light trap. Arabic numbers stand for dimensions of the devices, in $\mathrm{cm}$. A, aluminium handle; B, aluminium rectangular frame; $C$, nylon net (mesh size $400 \mu \mathrm{m}$ ); D, plastic ring; $\mathrm{E}$, nylon stocking; $\mathrm{F}$, nylon collecting bag (mesh size $500 \mu \mathrm{m}$ ); G, collecting bag fixing device; H, PVC suction tube; I, pressure regulator; J, suction force regulating screw; K, compressed air injector; L, flexible suction tube; M, $2 \mathrm{~kg}$ lead weight; $\mathrm{N}$, nylon anchoring rope (ø $2 \mathrm{~mm}$ ); O, diving emergency light stick; $\mathrm{P}, 1.5 \mathrm{~L}$ plastic bottle; Q, vertical slits; R, float; S, Posidonia oceanica_L.) Delile leaves; T, bottom. 


\section{RESULTS AND DISCUSSION}

In total, 1005 amphipods have been captured, belonging to 32 species distributed over 18 families. Values of essential community parameters and diversity indices vary widely according to the method considered (table I).

The hand-towed net method allowed collection of a large number of animals, thanks to the wide surface covered in each sample. However, this method leads to low community density estimates ( 3 ind. $/ \mathrm{m}^{2}$ during daytime), which could indicate a lack of efficiency of the method. Samples collected by hand-towed net also show low $d$ and $H^{\prime}$ values, and contained few species. These samples were very strongly dominated (up to $94 \%$, in the case of the night sample) by individuals belonging to the genus Apherusa, and had low $J$ 'values. These results suggest that the hand-towed net collected mainly species directly associated to the foliar stratum of the meadow, and is rather inefficient in capturing animals from the lower layers of the meadow. Besides this, it is important to consider that the hand-towed net is an "easy-to-use" method, which allowed the collection of samples during both day and night. The night sample was by far richer in individuals and species than the daytime one. This tends to confirm the hypothesis of a nocturnal rise of amphipods from the lower layers to the meadow canopy (Sánchez-Jerez et al., 1999b).

At daytime, the air-lift method was more efficient than the hand-towed net. The air-lift indeed captured more individuals, belonging to more species and more families. It also led to much higher community density estimates (more than $380 \mathrm{ind} . / \mathrm{m}^{2}$ ), and air-lift samples showed higher values of $d$ and $H^{\prime}$. Furthermore, the dominance of the species of the genus Apherusa was weaker (about $55 \%$ of the sampled individuals). This method thus seems more appropriate than the hand-towed net for the collection of amphipods from $P$. oceanica meadows, and is presumably more suitable for quantitative purposes. Nevertheless, it has disadvantages. First, it damages the sampled organisms, sometimes leading to unindentifiable specimens $(2.6 \%$ of the individuals, in the present case). Second, it is much more demanding in technical and human means than the hand-towed method. This last disadvantage makes this method hardly applicable during the night, which is, however, the most interesting period to sample the concerned organisms.

The light traps method collected fewer individuals than the hand-towed net during the night, but this sample contained much more species from much more families than any other one. Moreover, it showed the highest values for $d, H^{\prime}$ and $J$ '. The dominance of the genus Apherusa was weak, with Apherusa chiereghinii being only the second species (less than $10 \%$ of the sampled individuals). The use of light traps thus seems the most suitable method for the study of amphipod specific diversity in $P$. oceanica meadows, or to collect rare species. Furthermore, this method requires little underwater work, and integrates data over a whole night, whereas the others only give a snapshot of the composition of the community. However, this method is completely inefficient during the day (L. Michel, unpubl.). In addition, it implies active movement by the animals, which raises the question of "contamination" of these samples by animals attracted by the light from adjacent habitats. Finally, the action radius of a light stick is unknown, preventing any quantitative considerations.

\section{CONCLUSIONS}

Each of the methods used shows advantages and disavantadges. The most important feature to consider in the choice of the method would be its adequacy with regard to the study purpose. For example, the hand-towed net is an easy and rapid method to obtain a large number of amphipods of the dominant species. This sampling mode is suitable for trophic studies, or in vitro eco-physiological studies. This method also allows the collection of samples during both night and day, and is thus interesting for studies concerning diel migrations. However, it is likely that this method mainly collects animals from the foliar stratum of the meadow only. Air-lift is undoubtedly the best method to near quantitative estimates, and is thus interesting in biodiversity surveys, but it is technically demanding and not really adapted to night sampling. Moreover, it tends to be more damaging to organisms than the other methods. Light traps are an easy and interesting alternative to collect the rarest species of the community. Nevertheless, they are of questionable representativeness, and unable to yield reliable density estimations.

Besides these considerations, it is important to remember that the vagile invertebrate community of $P$. oceanica meadows is complex and dynamic (Mazzella et al., 1989 ; Sánchez-Jerez et al., 1999b). The gross differences observed in the samples obtained by different methods may come from the fact that they reflect different partial aspects of a more complex community. The most accurate way to sample amphipods from $P$. oceanica meadows could thus be to combine several methods, keeping in mind their specific strengths and weaknesses, and to adapt the sampling to the 
Table I

Values of community parameters and diversity indices for each of the techniques used to sample the amphipod community of Posidonia oceanica (L.) Delile meadows; units are between parentheses.

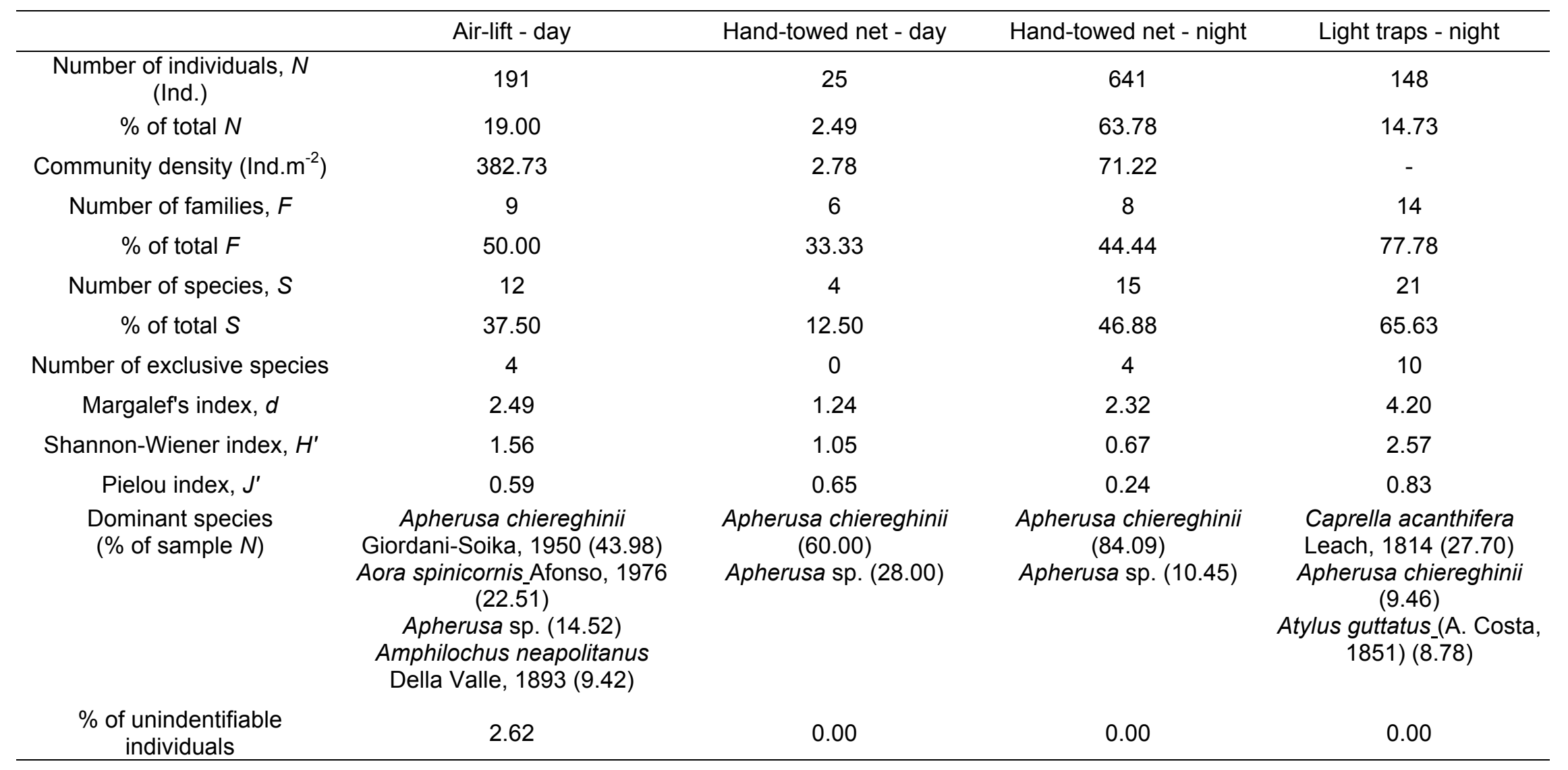


aim of the study. For example, in this study, the conjoint use of air-lift during the day and light traps during the night would have allowed the capture of nearly $90 \%$ of the species sampled in this study, making this combination a suitable way to evaluate the specific diversity of the sampling area.

\section{ACKNOWLEDGEMENTS}

The authors would like to thank the staff of the STARESO research station for their help in the field work, as well as Renzo Biondo (Laboratory of Oceanology, University of Liège) for his technical assistance in the development of the sampling devices. LM is a research fellow (grant nr. FC073734) of the Belgian National Fund for Scientific Research (FNRS), and NS is funded by a doctoral grant from the Belgian Fund for Research for the Industry and Agriculture (FRIA). This work was partly supported by the French Community of Belgium ("RACE" Project, ARC-05/10-333). This study is MARE publication nr. 165.

\section{CITED REFERENCES}

Bellan-Santini, D., G. Diviacco, G. Krapp-Schickel, A. A. Myers \& S. Ruffo, 1989. Gammaridea (Haustoridae to Lysianassidae). In: S. RUFFo (ed.), The Amphipoda of the Mediterranean, 2. Mém. Inst. océanogr. Monaco, 13: 365-576.

Bellan-Santini, D., G. Karaman, G. Krapp-Schickel, M. Ledoyer, A. A. Myers, S. Ruffo \& U. SCHIECKE, 1982. Gammaridea (Acanthonozomatidae to Gammaridae). In: S. RUFFO (ed.), The Amphipoda of the Mediterranean, 1. Mém. Inst. océanogr. Monaco, 13: 1-364.

Bellan-Santini, D., G. Karaman, G. Krapp-Schickel, M. Ledoyer, A. A. Myers \& S. Ruffo, 1993. Gammaridea (Melphidippidae to Talitridae), Ingolfiellidea, Caprellidea. In: S. RUFFo (ed.), The Amphipoda of the Mediterranean, 3. Mém. Inst. océanogr. Monaco, 13: 577-813.

Bellan-Santini, D., G. Karaman, M. Ledoyer, A. A. Myers, S. Ruffo \& W. Vader, 1998. Localities and Map, Addenda to Parts 1-3, Key to Families, Ecology, Faunistics and Zoogeography, Bibliography \& Index. In: S. RUFFO (ed.), The Amphipoda of the Mediterranean, 4. Mém. Inst. océanogr. Monaco, 13: 814-959.

Bussers, J.-C., M. PouliceK \& G. DiePVINTS, 1983. Description d'une suçeuse à air comprimé économique et utilisable par un seul plongeur. Cah. Biol. mar., 24: 215-217.

Gambi, M. C., M. LoRenti, G. F. Russo, M. B. Scipione \& V. ZuPO, 1992. Depth and seasonal distribution of some groups of the vagile fauna of the Posidonia oceanica leaf stratum: Structural and trophic analyses. P.S.Z.N. I: Mar. Ecol., 13: 17-39.

JeRnakoff, P., A. BREARLEY \& J. Nielsen, 1996. Factors affecting grazer-epiphytes interactions in temperate seagrass meadows. Oceanogr. Mar. Biol. ann. Rev., 34: 109-162.

KRAPP-SCHICKEL, T. \& J.-C. SORBE, 2006. Apherusa delicata n. sp., a new suprabenthic amphipod (Crustacea, Eusiroidea, Calliopiidae) from the northern Bay of Biscay, with a discussion of the genus. Org. Divers. Evol., 6: 57-65.

MAZZELLLA, L., M. B. SCIPIONE \& M. C. BuiA, 1989. Spatio-temporal distribution of algal and animal communities in a Posidonia oceanica meadow. P.S.Z.N. I: Mar. Ecol., 10: 107-129.

Myers, A. A., C. C. McGrath \& R. KING, 2001. Keys to the Nort-East Atlantic and Mediterranean amphipods. Interactive keys available at http://www.amphipoda.com, accessed on 23/08/2006.

Russo, G. F., E. FRESI, \& D. VINCI, 1985. The hand-towed net method for direct sampling in Posidonia oceanica beds. Rapp. Comm. int. Mer Médit., 29: 175-177.

Russo G., D. VINCI, M. SCARDI \& E. FRESI, 1991. Mollusc syntaxon of foliar stratum along a depth gradient in a Posidonia oceanica Bed : 3. A Year's cycle at Ischia Island. Posidonia Newsletter, 4: 15-25.

Sánchez-Jerez, P., C. Barberá-Cebrián \& A. A. Ramos-EsplÁ, 1999a. Comparison of the epifauna spatial distribution in Posidonia oceanica, Cymodocea nodosa and unvegetated bottoms: Importance of meadow edges. Acta Oecol., 20: 391-405.

$-\ldots,--\&-\ldots, 1999 \mathrm{~b}$. Daily vertical migrations in the epifauna associated with Posidonia oceanica meadows. J. Mar. Biol. Ass. U.K., 79: 971-977.

SCIPIONE, M. B. \& E. FRESI, 1984. Distribution of amphipod crustaceans in Posidonia oceanica (L.) Delile foliar stratum. In: C.-F. Boudouresque, A. JeUdy de Grissac \& J. Olivier (eds), International Workshop on Posidonia oceanica Beds, 319-329. 